\title{
LA ORATORIA SAGRADA Y LA IMAGEN IDEAL DE LA INFANCIA
}

\author{
Sacred oratory and childhood ideal image
}

\section{Karina Clissa*}

\section{Resumen}

El artículo realiza un análisis del púlpito en el período colonial y postcolonial, como un espacio público desde donde se exponían múltiples mensajes, tendientes todos ellos a instruir a la feligresía sobre aspectos espirituales -ligados por ello al plan salvífico- pero también sobre prácticas y conductas en torno a arquetipos modélicos. En ese contexto, la predicación solía hacerse eco de aspectos relacionados con la existencia doméstica y la importancia de la familia en la educación de los niños.

$$
<\text { Infancia }><\text { Oratoria sagrada }><\text { Sermón }><\text { Persuasión }>
$$

\begin{abstract}
This article analyzes the pulpit as a public space where multiple messages were displayed, during the colonial and postcolonial periods. These messages were designed to instruct the faithful in the spiritual aspects -being such messages thus related to a salvific plan-, but also in exemplary practices and behaviors constructed around archetypes. In this context, preaching used to be based on topics related to domestic existence and the importance of the family in the education of children.
\end{abstract}

$<$ Childhood $><$ Sacred oratory $><$ Sermon $><$ Persuasion $>$

Recibido: 10/05/2016 // Aceptado: 16/09/2016

\section{A manera de introducción}

El período colonial americano ofrece infinidad de documentación, a partir de la cual uno puede acceder a las variadas formas de comunicación que tuvieron lugar en aquel entonces. Esos textos que han logrado perdurar en el tiempo -entre los que se pueden mencionar los sermones- ofrecen la posibilidad de explicar las funciones de argumentación, persuasión y expresión estética y comunicativa de un mensaje que

\footnotetext{
Doctora en Historia. Universidad Católica de Córdoba, Centro de Estudios Históricos "Prof. Carlos S. A. Segreti”.karinaclissa@yahoo.com
} 
mostraba cierta rigidez y un carácter estricto de la doctrina y la moral y que, al mismo tiempo, procuraba crear un clima capaz de impactar en el mundo familiar.

En los últimos años, se asiste a un crecimiento exponencial en la historia de la familia y en su interior, en la perspectiva del estudio de la infancia, como uno de los campos más activos del enfoque sociocultural. El tema de la infancia ha adquirido una especial atención e interés entre los investigadores, en virtud de los diversos puntos de vista desde los cuales se analiza, así como las fuentes de que se dispone y las orientaciones metodológicas a partir de las cuales se aborda dicho objeto de estudio. Ligado a esto, se evidencia una nueva representación social de la niñez por parte del mundo adulto, producto de los cambios sociales y políticos que se han venido sucediendo.

Un documento histórico es capaz de albergar un contenido que, leído e interpretado adecuadamente, abre las puertas al conocimiento de diferentes dimensiones de la vida social de otras etapas del pasado. De lo que se trata es de recobrar el valor de la palabra, del sentido del discurso, de la eficacia de la retórica, del compromiso de quien habla y de qué se dice en torno a los niños en el contexto del púlpito (García García, 2005). En el caso específico de los sermones, lo que se encuentra es la presencia de textos en donde, mientras se avanza entre reflexiones y argumentaciones, se van ofreciendo "miradas diversas" sobre el tópico central de la prédica.

La palabra era capaz de crear reconocimiento de cada sujeto en el escenario colectivo, a la vez que servía para estructurar la sociabilidad. Por medio de la palabra, se valoraba una situación considerada modélica y, simultáneamente, se situaba a cada uno de los fieles en relación con ese esquema ideal.

El trabajo -el cual se sitúa en continuidad con las investigaciones que se vienen desarrollando en el Proyecto titulado El "deber ser" en la oratoria sagrada rioplatense (siglos XVIII y XIX)-, apunta a rescatar, en el entramado de la práctica pastoral que sostuvo la Iglesia, un corpus de piezas oratorias en las cuales es factible rescatar la imagen y caracterización en torno a la temática familiar e infantil.

¿Cuáles son las imágenes y narrativas que hacían a la construcción social de la niñez en tales piezas oratorias? ¿Cuál era la visión de la infancia que la Iglesia dejaba traslucir a través de la predicación? ¿Cuál era la representación cultural de los sentimientos que los niños generaban en el entorno social? Constituyen éstos algunos de los interrogantes a partir de los cuales se buscará ahondar en la función social de la infancia y el rol de la familia como reforzadora del aprendizaje y las conductas adaptativas en un determinado tiempo y espacio.

Investigaciones recientes han demostrado que el estudio detallado del discurso puede revelar propiedades del contexto social y de las instituciones que, de otra manera, serían difíciles de precisar. Hoy más que nunca, las Ciencias Sociales necesitan describir y explicar no sólo grandes y abstractas estructuras sociales, sino también el micronivel, en el que tales estructuras se producen, es decir, lo que realmente sucede en la vida cotidiana, a través de lo que se dice, tanto en textos normativos como literarios, pues de esa manera resulta factible recuperar indicios de las formas de interacción de los actores sociales. 
Se trata de una investigación de carácter diacrónico, ubicada en el período colonial y primeras décadas de la independencia, en la que se buscará dar cuenta de microestructuras básicas referidas a diferentes aspectos del comportamiento en general de la sociedad, de formas de la religiosidad en particular, actitudes y concepciones de los diferentes grupos sociales $\mathrm{y}$, en especial, del estamento eclesiástico como productor de textos en los cuales la figura del niño no estuvo ausente.

Paralelamente se recurrirá al método histórico-genético, en cuanto importa conocer qué se dijo y en qué circunstancias vitales de la sociedad, para descubrir las constantes adecuaciones que tuvo el texto en su inserción en un contexto local pero que, a su vez, debía ser válido para "otros", ya que se repetía en diferentes o iguales circunstancias, con apropiaciones y reelaboraciones adecuadas a cada caso.

\section{Desde el entorno del púlpito}

A lo largo del período colonial y tardocolonial, el templo funcionó como el ámbito por excelencia para convocar a los individuos de diferentes grupos sociales, quienes acudían a escuchar misa, a recibir los sacramentos, a rendir culto a las imágenes y reliquias y a participar activamente en las fiestas propias del calendario litúrgico. Allí, los fieles no sólo cumplían con sus obligaciones y devociones religiosas sino que, al mismo tiempo, eran formados en la fe católica e informados sobre lo que se esperaba de ellos en la vida cotidiana. El sermón, entendido como un medio de comunicación de múltiples mensajes, ha sido el objeto de estudio del presente trabajo, orientado a rescatar la importancia del lenguaje como elemento constituyente de la realidad y componente capaz de fortalecer la identidad de un grupo social. El lenguaje puede ser una herramienta para acercarnos al universo simbólico en el que se inscribía y cobraba sentido la vida de los seres humanos y como tal, constituye un producto capaz de dar cuenta de la realidad subjetiva y social.

Desde el púlpito se exponían ejemplos sobre los modos y formas de reglar al conjunto de habitantes de tan disímiles características biológicas, diferentes prácticas culturales y peculiares costumbres. Eran discursos eminentemente prescriptivos a partir de los cuales operó el proceso de construcción de arquetipos sociales en torno a la tríada padre-madre-hijos, en tanto elementos fundamentales en la conformación de la familia nuclear (Sanchiz, 2005).

De esa manera, los concionadores trataban de instalar en la sociedad de su tiempo modos de pensar, sentir y actuar relacionados con la vida terrenal y, a partir de ella, con la que debía ser la máxima aspiración en el "más allá".

La persuasión constituía el principal recurso de la oratoria, porque todo estaba encauzado a que se cumplieran cada uno de los fines y propósitos del discurso (Martínez de Sánchez, 2013). La palabra discurría en un entorno cuidadosamente preparado y encaminado a "domar los comportamientos y las actitudes de los fieles", con el fin de instalar prácticas de abnegación y compasión para ensamblar el cuerpo social (Arce Escobar, 2009). 
El mandato de la predicación, la cual debía ser digna y frecuente, solía incluir a sujetos diversos -entre los que figuran los niños- y donde los modelos que se seleccionaban se basaban en la moral cristiana. Se recurría así, a la Biblia, a los Padres de la Iglesia y a la literatura piadosa.

El lector actual que se aproxima a estas piezas oratorias o a los manuales de sermones debe llevar a cabo un ejercicio de abstracción mental para estar en condiciones de diferenciar el mensaje que conllevaba la prédica del sermón en tanto discurso oficial de las prácticas concretas y reales que luego se concretaban en la sociedad hacia la cual estaban orientados los temas que se exponían en el púlpito. Es probable que existiera una distancia entre el fin de persuadir a un auditorio y lo que la grey cumplía efectivamente (Martínez de Sánchez, 2013). No obstante, queda claro que la Iglesia buscaba convencer y concienciar a las personas sobre los modelos que debían seguir y donde la infancia aparecía también como un tópico sobre el cual reflexionar. Sin duda, la tarea de adaptar la prédica al auditorio específico y persuadirlo era una forma también de impactar en el hacer de los fieles.

Decía un predicador:

"Los sentimientos que nuestros padres nos inspiraron desde la infancia, os los inspiraría por el canal de la tradición, con tan buena fe como los recibí de ellos; persuadido, como añade como añade este sabio del siglo quinto, a que el verdadero carácter de la gravedad cristiana, es conservar religiosamente lo que se ha recibido de sus antepasados sin novedad, ni opinión: Audivimus. Abrid la historia de los tiempos, y hallaréis una cadena de tradición continuada por diez y ocho siglos, y jamás interrumpida desde el nacimiento de la Iglesia: veréis el canal puro por donde las bellas cualidades que predico de la Santísima Virgen, han llegado desde nuestros padres sucesivamente hasta nosotros"1.

En el acto de argüir, de dar indicios y muestra de lo que se pretendía, la postura adoptada era organizada siguiendo una lógica consistente en "dar razones”. El objetivo central era la persuasión -como parte de la sensibilidad religiosa del barroco- , la cual estaba acompañada del arte del buen decir, consistente en instruir, convencer y movilizar con la palabra (Terán Fuentes, 2002). En definitiva, la meta -de índole argumentativa y persuasiva- estaba orientada a acercar lo intangible a la condición humana mediante visiones, audiciones y la propia palabra de Dios (García Bernal, 2008). Tarea compleja que requería del manejo adecuado de mecanismos lógicos, comunicativos y psicológicos (Marimón Llorca, 2006).

1 Pantaleón García. Sermones panegíricos de varios misterios, festividades y santos. Tomo II, Sermón VI Nuestra Señora de Copacabana, Madrid, Imprenta Collado, 1804, pp. 163-192 


\section{La familia como realidad histórica}

La importancia asignada a la familia en la América colonial fue decisiva, teniendo en cuenta que esa organización social fue traída por los conquistadores y así logró perdurar a través de los siglos. Fue concebida como una institución social en el sentido que constituía una estructura cultural de normas y valores, organizada por la Corona española para regular la acción colectiva. Dicho escenario estuvo, a su vez, impregnado por la necesaria atención a la función religiosa que cumplía toda familia (Páez Morales, 2006). La norma mostraba la cara del "deber ser", no solo con aportaciones de la legislación castellana, sino también con las normas cristianas tridentinas (Gonzalbo Aizpuru, 1998). La norma era una forma de estipular los parámetros desde los cuales los individuos debían actuar y desenvolverse. Al respecto, el Padre Arbiol afirmaba:

"Desde el principio del mundo dispuso la Divina Providencia, para la propagación legítima del Género Humano, el estado decente y honesto del Santo Matrimonio. [...] No solo dispuso el Altísimo el estado del santo Matrimonio para la creación de los hijos, y propagación del linaje Humano, si también para templar y regular la lujuria libidinosa que quedo desordenada y desenfrenada por el pecado original"'.

En el diseño del sistema social concebido por la Iglesia y apoyado por la Monarquía católica, se reconoce la importancia atribuida a la institucional matrimonial, en tanto entrega mutua de las almas y de los cuerpos y destinada a la procreación de los hijos y para remedio de la concupiscencia (Ghirardi e Irigoyen, 2009). El mutuo consentimiento del varón a la mujer y de la mujer al varón eran, por tanto, la materia y la forma de este sacramento; de manera que la entrega voluntaria era la materia, y la aceptación de los contrayentes era la forma. La defensa del matrimonio implicaba, al mismo tiempo, la defensa de un modelo de sociedad que la monarquía española buscó implantar en la América colonial a lo largo de los siglos. El matrimonio fue considerado un sacramento santo y útil tanto a la Iglesia como a la Corona e imprescindible a ambos. Se lo percibía como una institución recomendable y de loables fines, digna de ser favorecida, en tanto constituía el medio por el cual se formaban las familias y se aseguraba que la sociedad contara con individuos que vivieran en esa tan ansiada "paz y quietud".

Dentro de la familia regulada bajo tales parámetros, el hombre figuraba como amo y señor de todo, en tanto que la esposa era responsable sumisa de lo que ocurría con la economía doméstica, los hijos y los criados. La relación conyugal no era de iguales, sino de subordinante y subordinado, donde los maridos tenían una posición privilegiada, porque gozaban de la autoridad suficiente como para controlar a su esposa y a la prole. Sin embargo, esas relaciones eran también complementarias, lo que seguramente le

2 R. P. Fr. Antonio Arbiol. La familia regulada, con doctrina de la Sagrada Escritura y Santos Padres de la Iglesia Católica. Madrid, Imprenta Real, 1791, lib. I, cap. I. 
permitió a don Juan Asensio Martínez reconocer en su testamento -hacia 1777- que en su matrimonio se habían mantenido ayudándose "el uno al otro"3.

La Iglesia prescribía una moral jerárquica entre varones y mujeres, donde el hombre estaba llamado a saber mandar y la mujer a obedecer y callar, aunque paralelamente a esta concepción, los cónyuges se ensamblaban en una intimidad espiritual y emocional.

La buena esposa era la sumisa, honrada, fiel, obediente, modesta y recatada. De tales virtudes se desprendía su manera de actuar: gravedad para salir, cordura para gobernar la casa, paciencia para sufrir al marido, amor para criar los hijos, afabilidad para con los vecinos, diligencia para guardar la hacienda, amiga de buena compañía y muy enemiga de las liviandades y ociosidades. El ejercicio de estas virtudes la circunscribían en la práctica a los límites del hogar, donde estaban centralizadas todas sus tareas.

Quienes tuvieron la responsabilidad de estructurar la familia como célula primera de la sociedad y trazaron las ideas rectoras, lo hicieron con la convicción de que constituía el único camino posible en una república cristiana.

\section{La concepción de la niñez}

La labor formadora y moralizadora hacia los niños y jóvenes estuvo asociada con el rol materno, así como el resguardo de la reputación de las doncellas constituía una preocupación familiar (Ghirardi e Irigoyen, 2009).

Hablar del lugar asignado a los niños no constituye una tarea sencilla, resultado de su poca "visibilidad social". En ocasiones, las referencias que se hallan en las fuentes son tangenciales, por cuanto aparecen asociados a lo que les acontecía a los adultos y a la comunidad en general.

Con base en el análisis textual se ha buscado rastrear los textos producidos por la Iglesia, procurando identificar en ellos el modo en que se referían a la infancia, tema que lejos de ser mundano, se volvió relevante puesto que implicaba referirse a roles que debían encarnar, de la mejor manera posible, padres, madres e hijos.

Como primera aproximación, se puede señalar que la infancia aparecía asociada a la edad que combinaba la fragilidad física, la vulnerabilidad emocional y el desarrollo intelectual en proceso (Pedraza Gómez, 2007). De allí que se insistía en la conducta que debían tener los padres frente a la mirada atenta de los hijos.

"Aprendan a abstenerse de las palabras, acciones y llanezas que en ellos hace licitas el matrimonio y vistas de sus hijos, pueden ser para sus hijos veneno, porque aún no tienen calor para discernir, y digerir"'4.

Lo social obraba en un doble sentido: como factor activante en el desarrollo de los infantes y como factor formante, en virtud de la experiencia social de los sujetos y

\footnotetext{
3 Archivo Histórico de la Provincia de Córdoba (en adelante AHPC), Registro 3, 1777, f. 74 v.

4 Josef de Barcia y Zambrana. Despertador cristiano. Madrid, Por Francisco del Hierro, 1727, p. 229.
} 
lo que se aprendía como resultado de la interacción entre los individuos en el seno del hogar.

Frente a esa fragilidad propia de la edad, el niño también gozaba de una destacada potencialidad, en tanto promesa de lo que podría llegar a ser en su etapa adulta, lo que a su vez era resultado de la protección, la educación y la corrección constante (Amador Baquiro, 2012). Estaban en camino de alcanzar el máximo nivel de desarrollo y realización, como parece insinuar Pantaleón García cuando indicaba que un niño podía perecer antes de "llegar a la edad de hombre"s.

Lo cierto es que, en el contexto del sermón, había una percepción cultural de la infancia en tanto etapa que preparaba y a la vez anticipaba la madurez y entonces el cuidar a los niños debía darse en consonancia con la enseñanza de destrezas, habilidades y competencias (Pedraza Gómez, 2007).

Plantear la cuestión de la infancia como una construcción social e histórica, implica reconocer el aporte que ha significado en su momento el trabajo clásico de Philippe Ariès (1987). A partir de allí, los estudios en torno a la infancia han revelado un crecimiento cualitativo en el ámbito de las Ciencias Sociales a nivel mundial (Marín Guadarrama, 2012). No obstante, el estudio de ese grupo etario no es un concepto accesible por cuanto es necesario rastrear en cada época los puntos de referencia que marcaron la realización plena del niño (Gutiérrez, 2013).

En consonancia con ello, la historia cultural y la historia de las mentalidades han contribuido también a la constitución de la infancia como campo de investigación, al evidenciar las representaciones sociales del niño y su evolución a lo largo de los siglos (Caspard, 2001).

Según el criterio de la época, la niñez conformaba esa primera etapa de la vida de una persona -edad pueril- que solía extenderse, aproximadamente, hasta los 10 o 15 años ${ }^{6}$.

La expresión "roles de género" apunta al conjunto de expectativas respecto al comportamiento, las actitudes y actividades apropiados en hombres y mujeres. Tradicionalmente se pensaba que la dureza era un rasgo masculino y que la ternura estaba asociada a lo femenino.

En su condición de agentes socializadores, los padres cumplían un papel primordial en la tarea de guiar a los niños en esos roles de género que la sociedad había fijado como dignos de ser imitados. En otras palabras, una cultura es capaz de establecer los parámetros bajo los cuales cada sexo debe hacerse responsable de aspectos cruciales, tales como, la responsabilidad en la educación de los niños o el sostenimiento económico de las familias. Como correlato, el niño lograba desarrollar un modelo previo de lo que

5 Colección documental "Monseñor Dr. Pablo Cabrera, Córdoba: Biblioteca Central "Elma Kohlmeyer de Estrabou" de la Facultad de Filosofía y Humanidades de la Universidad Nacional de Córdoba, ex Instituto de Estudios Americanistas (en adelante IEA, para mantener la identificación histórica de la colección), doc. $n^{\circ} 11.721$, f. 8 r.

6 Esteban de Terreros y Pando. Diccionario castellano con las voces de ciencias y artes. Madrid, viuda de Ibarra, Tomo II, 1786-1787, p. 666. 
significaba vivir en sociedad, estar casado y ser padre o madre; a partir de lo que había podido observar en sus padres respectivamente (Schaefer, 2006).

Los niños van a ser concebidos en la época colonial como seres en condiciones para aprender, portadores de cualidades producto de la particularidad individual y social de cada uno. Pero, por sobre todo, resultaban de suma trascendencia, las prácticas intersubjetivas hacia los infantes y las relaciones que el conjunto de la sociedad entablaba con ellos.

Es factible recuperar aquí un fragmento de un sermón pronunciado por el Doctor Diego de Zabaleta en 1810, en donde reconocía los atributos de la infancia y los cambios que el proceso de socialización iba provocando en el hombre, el cual, había nacido "independiente, libre, árbitro, y soberano de sus acciones. ¿Estos privilegios del género humano en su infancia debieron cesar en su adolescencia, no habiendo en este estado más ley, que la que imponía el más fuerte?’’.

La memoria del hombre era frágil y podía no recordar cuando la humanidad estaba en sus albores y aparecía imbuida de rasgos propios de la niñez, con sensaciones e impulsos que luego fueron mesurados conforme las comunidades adquirían complejidad. Más que marcar la idea de cambios graduales y paulatinos, se optaba por mostrar el primer período de la vida de una persona como el tránsito de un estado -inferior en algunos aspectos- hacia otro superior, que se correspondía con la adultez.

En otras ocasiones, la prédica solía recuperar conductas y maneras de desenvolverse propias de ese momento de la vida y que resultaban positivas, por ejemplo, en el accionar de todo concionador. Se han encontrado ejemplos, en donde se conminaba a los religiosos a que fuesen "como niños", no para comportarse como párvulos sino para imitar su inocencia, por la cual serían capaces de tener oídos obedientes, "que oyen y creen cuanto se les dice como verdadero"8. Tales sugerencias servían sobre todo cuando se producía el encuentro con los fieles en el confesionario.

La espontaneidad solía ser también otra cualidad que se asociaba a los párvulos, tal como puede percibirse en el siguiente fragmento: "No me avergüenzo de decir con el Apóstol, que apurados mis pensamientos, hablaré como un niño; y por otra parte, mi alma fuera de sí, y hecha, digámoslo así, toda ojos, toda oídos, se halla como encantada"9.

No faltaron casos en donde se hizo alusión a la condición de "pureza e incontaminación", así como de "ternura, humildad, mansedumbre, docilidad, recogimiento, mesura" (Páez Morales, 2006). Y hasta hubo casos en donde se reconocía la función recreativa y lúdica, al señalar por ejemplo que disfrutaban de "travesear en las plazas"10.

7 IEA, doc. $\mathrm{n}^{\mathrm{o}} 12.480$, f. 3 v.

8 IEA, doc. $n^{\circ} 11.540$, f. 3 r.

9 Pantaleón García. Sermones panegíricos de varios misterios, festividades y santos. Tomo I, Madrid, Imprenta de D. Benito Cano, 1804, Sermón de Nuestra Señora de las Mercedes, pp. 159-194.

${ }^{10}$ IEA, doc. $\mathrm{N}^{\mathrm{o}} 11.721$, f. $5 \mathrm{v}$. 


\section{Las relaciones paterno-filiales}

La familia ha sido una constante a lo largo de la historia y en su tarea, la presencia de los hijos y de los cuidados que esa etapa demanda ha sido fundamental. La perspectiva permite hacer foco en la filiación, es decir, en la relación natural que unía a procreantes y procreados y al afecto sobre el cual se cimentaba dicho vínculo.

“¿quién de vosotros, pide pan a su Padre, y le da una piedra? ¿O si le pide un pescado le da una serpiente? ¿O si le pide un huevo le alarga un Escorpión? Pues si vosotros siendo malos sabéis dar a vuestros hijos unos dones buenos, cuanto más vuestro Padre celestial dará el bien a los que se le pidieren?"11

Esa filiación también era válida para comprender lo que unía a la humanidad en su conjunto con la divinidad, -en calidad de Señor absoluto y Padre Celestial-. En este tramo del proceso de entendimiento, se exponía cómo el alma debía estar en condiciones de estrecharse en una unión eterna con su Padre Dios.

Solía ser habitual observar en los sermones la referencia a los preceptos del cuarto mandamiento, sustentados en los valores de autoridad de los padres y el deber y obediencia de los hijos. El ambiente familiar, a menudo inmerso en una extrema religiosidad, ayudaba en la tarea de crianza de los hijos.

La ley cristiana establecía que los padres estaban obligados a alejar a su descendencia de cualquier tentación o peligro que los hiciera dudar y distanciarse de la senda modélica, bajo la convicción de que "madruga mucho la malicia en las criaturas"12.

Paralelamente, el amor y la voluntad eran términos habituales en tales discursos, pero con la advertencia de que no se debían sobrepasar los límites,

"El Espíritu Santo previene a los padres de familia, que no sean como leones en su casa, oprimiendo y aterrando a sus familias, sino que los corrijan como racionales, haciendo con ellos el oficio de padres, y no el de tiranos"13.

La "excesiva ternura" y la "falta de un castigo a tiempo" podían convertir a los hijos en "seres blandos" e "inclinados a los vicios"14. En este sentido, buenos padres eran aquellos capaces de practicar una severidad benigna, unas veces con firmeza y otras con discreta templanza, para que si las hijas erraban el camino, no fuera por culpa de ellos sino por "sobra de su malicia". El escritor Cristóbal de Aguilar se ocuparía en varias de sus obras de abordar en detalle la temática del vínculo matrimonial y las relaciones familiares, recurriendo de manera didáctica al empleo de descripciones de conductas contrapuestas con el propósito de destacar aquellas que estimaba correctas

${ }^{11}$ IEA, 11.690, Sermón de Rogativa por falta de agua a Nuestra Señora de los Remedios, 1797, f. 2 r.

12 Antonio Arbiol. La familia regulada ..., ob. cit., lib., IV, cap. 2.

13 Antonio Arbiol. La familia regulada..., ob. cit., lib., IV, cap. 2.

${ }^{14}$ Antonio Arbiol, La familia regulada..., ob. cit., lib. 5, cap. 1. 
y adecuadas ${ }^{15}$. El contraste era un buen recurso empleado en las piezas teatrales, en la medida que, por oposición lograban reforzar el sentido o la dirección del argumento. En El triunfo de la prudencia y fuerza del buen ejemplo, se encuentra el siguiente texto que pronuncia don Elías, reflexionando disgustado por el gasto excesivo que hacían semanalmente su esposa y su hija:

"Esta mujer y esta hija, si yo callo, me destruyen, y el silencio en este caso es muy malo.

Si la increpo algo severo, su altivez y su descaro me pondrá en un precipicio. Elías, ¿qué es lo que hago?

$$
\text { [...] }
$$

Don Eduardo y su esposa

doña Estefanía, entrambos pueden ayudarme mucho: son finísimos dechados de moderación en todo"16.

\section{Así lo reconocía Antonio Arbiol:}

"Salomón dice, que no apartes la disciplina del niño, ni temas se morirá por azotarle, porque en aquellos primeros años de la niñez no corre el peligro de la precipitación referida. El que perdona a la vara y a la disciplina, aborrece a su hijo, dice el mismo Sabio" "17.

En su calidad de primeros agentes de socialización, los padres cumplían un papel primordial en la loable tarea de guiar a los niños en esos roles de género que la sociedad había fijado como correctos y dignos de ser imitados. En otras palabras, la concepción de la época establecía los sujetos sobre los cuales recaía la responsabilidad básica en la educación de los niños y la labor de sostener económicamente a la familia.

Para alcanzar tales metas, el discurso católico solía dotar al mundo familiar de gestos y actitudes que propiciaran la armonía y la paz entre los esposos, lo que a su vez impactaría positivamente en la instrucción de los hijos y contribuiría a la paz social. Como correlato, el niño estaba en condiciones de ir visibilizando un modelo previo de lo que se esperaba cuando creciese, a partir de los comportamientos que había sido capaz de observar en sus padres (Schaefer, 2006).

Es innegable que la rigidez de las leyes y el carácter estricto de la doctrina y la moral que se preconizaba en obras como la de Arbiol -que hemos tomado como ejemplo,

${ }^{15}$ Cristóbal de Aguilar, Obras, con estudio preliminar de Antonio Serrano Redonnet, Daisy Rípodas Ardanaz y otros, Biblioteca de Autores Españoles, vol. I, Madrid: Ediciones Atlas, 1989, p. LXXXIX.

${ }^{16}$ Ibidem, vol. II, 1990, p. 159, (vv. 102-108 y 117-121).

17 Antonio Arbiol, La familia regulada ..., ob. cit., libro IV, cap. 18. 
entre muchas otras que se editaron en los siglos coloniales-, también se hicieron presentes en los discursos religiosos correctivos que formaron parte de la oratoria sagrada de la época. En todas esas expresiones se ofrecían escasas posibilidades de vivir fuera de tan férrea concepción.

"De semejante casa infeliz, dixo Dios por uno de sus Profetas, que pensaba enviarle muchos daños y castigos [...] Y examinando la causa, en el mismo Sagrado Texto se halla, que era una familia perdida, de malas costumbres, sin temor de Dios, y con muchísimos vicios, y los principales de la familia consentían en todo, sin reprehender ni corregir a los de su casa; por lo cual determino Dios acabar con ella"18.

\section{La acción educativa}

Educar y criar a los niños implicaba cuidado físico, disciplina, obediencia y amor a Dios. La naturaleza infantil requería ser educada, es decir, reformada, para adaptarse a los esquemas modélicos de la sociedad. Y la mejor manera de lograrlo era mediante la experiencia y la práctica de los hábitos que, a largo plazo, iban dejando huellas en los sujetos.

¿Cómo hacía el orador sagrado para lograr que el mensaje de la prédica fuese interpretado de una forma adecuada? Sus opciones incluían un abanico de palabras, relatos y ejemplos simples, para que el auditorio lograse comprender la esencia del mensaje. Debía ser capaz de articular y complementar lo divino con lo humano. El criar a los hijos podía compararse a la tarea de un jardinero que demuestra esmero y dedicación al plantar un arbolito y cuidarlo (Chinchilla Pawling, 2004).

Las prácticas eran esas acciones aprendidas dentro de las relaciones de crianza en las cuales los adultos estaban siempre involucrados. La pauta era el canon que orientaba las acciones de los padres hacia los hijos, en consonancia con el orden normativo y las determinaciones culturales vigentes. Paralelamente, las representaciones sociales aparecían como imágenes colectivamente compartidas que se tenían en torno a la crianza y a la naturaleza infantil. Eran explicaciones y certezas respaldadas por los miembros de la comunidad (Bocanegra Acosta, 2009).

Los sermones debían mostrar la fuerza de las verdades que todo fiel estaba llamado a creer y para ello la Iglesia disponía de una serie de acontecimientos históricos que poseían un valor en términos religiosos y era útil por tanto recurrir a ellos una y otra vez. La legitimación de dichos períodos demostraba la fuerza de los mismos y su condición para influir sobre las conductas cotidianas.

Aprender era una cualidad de todo niño, sostenía Tertuliano, como así también el crecer en la virtud y el "descuidarse" para resignarse todo en su padre. Eso mismo debería darse en el cristiano, dispuesto a llevar a una vida de virtud y "resignarse todo

\footnotetext{
18 Antonio Arbiol, La familia regulada..., ob. cit., libro IV, cap. 1.
} 


\section{DOSSIER}

Clissa. La oratoria sagrada y la imagen ideal de la infancia.

en Dios". Y finalizaba dicha comparación afirmando: "O Christianos, y que pocos se perdieran si trataramos de volvernos como niños!"19

El adulto -y por sobre todo, los padres con hijos- eran los encargados de educar a los niños en la doctrina cristiana, en los mandamientos que debían guardar, los sacramentos que debían recibir, las oraciones con las que podían comunicarse con Dios, las virtudes que debían ejercitar y los vicios de los que debían apartarse ${ }^{20}$.

El esmero que debía ponerse en que los infantes se educaran en la fe católica estaba ligado a la preocupación que trascendía la vida terrenal y con el ideal de santidad al que todo creyente estaba llamado a encarnar. Si bien esa meta podía presentarse un tanto alejada de la práctica cotidiana, funcionaba como brújula y como máxima aspiración de una padre para con su hijo. Eran los miembros de la familia los encargados de estar atentos para observar y corregir cualquier comportamiento de los niños que se alejara de tal propósito.

Por ello, la crianza de los niños ocupaba un lugar en el contexto de la prédica de los concionadores, convencidos que lo que un padre hacía en relación a su hijo, repercutía luego en el escenario social.

"La primera instrucción que Tobías dió a sus hijos fue en la piedad y temor de Dios; y lo primero que nos enseñó el Señor fue la oración.

Sí, dice San Cipriano, el que nos dio la vida nos enseñó a orar, para que cuando enviamos nuestras súplicas al Padre Celestial, conozca este las palabras de su Hijo, y aplique sus: oidos con benignidad"21.

Los padres cristianos eran el "centro modélico" para sus hijos, "Vuestra vida es su pauta, su fuente, su raíz, para el bien y para el mal"22.

En ese escenario, casi como una constante, se podía focalizar principalmente en la interrelación que se daba entre una madre y su hijo, así como la influencia que ella era capaz de ejercer sobre su descendencia.

"En las madres se advierte cierta simpatía para imprimir en los hijos las propiedades de su corazon: en esto me son favorables los Filósofos. Luego si hay entre la madre y el hijo esta fuerte simpatía, que identifica, por decirlo así, los pensamientos y hace recíprocas los afectos, es muy cierto que los pensamientos y afectos de María que acompañaron la Concepcion del Verbo fueron todos de humildad"23.

\footnotetext{
${ }_{19}$ Josef de Barcia y Zambrana. Despertador..., ob. cit., p. 190.

${ }^{20}$ Juan Elías Gómez de Terán. Infancia ilustrada y niñez instruida en todo género de virtudes christianas, morales y politicas que conducen a la santa educación y buena crianza de los niños para que se use en la escuela. Madrid: Oficina de Antonio Marin, 1735, p. 35.

${ }^{21}$ Pantaleón García, Sermones panegíricos..., ob. cit., Tomo I, Sermón del Rosario de María Santísima, pp. 195-233.

${ }^{22}$ Josef de Barcia y Zambrana, Despertador..., ob. cit., p. 229.

${ }^{23}$ Pantaleón García. Sermones panegíricos..., ob. cit., Tomo I, Sermón V de la Visitación de Nuestra
} 
En el siguiente pasaje de La Familia Regulada, de Antonio Arbiol, encontramos referencias sobre el rol fundamental que las madres tenían en la educación de los hijos: "Atiendan las Señoras a aquellas insignes Matronas que ha tenido la Iglesia de Dios, y les dexaron glorioso exemplo para la buena crianza de sus hijos" ${ }^{24}$. Las madres eran capaces de orientar, educar y por sobre todas las cosas, estar presentes siempre al lado de sus hijos, inclusive en la enfermedad,

"Las madres observan con sus hijos enfermos una conducta muy diferente que los médicos. Cuando estos ven que sus remedios son inútiles, abandonan el enfermo: las madres no desamparan la cabecera de sus hijos, los animan y les dan de cuando en cuando refrigerio, permaneciendo a su lado hasta el último suspiro" 25 .

\section{Los "niños ejemplares"}

Existían numerosos textos de teología homilética que ayudaban a la preparación del sermón y donde se puede rastrear la referencia concreta que los concionadores podían hacer de algunos niños de la historia de la Iglesia. Así podemos encontrar ejemplos en la obra de Cristóbal de Avendaño, de la orden de Nuestra Señora del Carmen, Sermones para algunas festividades de las mas solemnes de los Santos, editado en Valladolid en $1629^{26}$.

En cuanto a relatos históricos, con niños involucrados, se podía hacer alusión a los niños de Babilonia ${ }^{27}$ o a San Juan Bautista, cuyo nacimiento era visto con grandeza y alegría, puesto que su nombre mismo significaba "gracia"28. No menos importante era el relato en donde la hija del faraón encontraba a Moisés fluctuando sobre las aguas en una cuna de juncos y ordenaba su crianza. El relato de los tres niños de Babilonia indica que Daniel se hallaba cautivo con los niños Ananías, Misael y Azarías y el rey Nabucodonosor estableció que se eligieran a los niños cautivos más agraciados, ágiles y doctrinados para instruirlos en la lengua (Gómez de Terán, 1735).

El sentimiento de afectividad que rodeaba a los niños, se expresaba sobre todo en la sermonística, a través de las figuras de la Virgen Niña y del Niño Dios. El culto a ambos fue propiciado por la Iglesia católica luego del Concilio de Trento.

En lo referido a la Virgen Niña, de lo que se trataba era de anticipar su rol protagónico como futura madre de Dios (Valdivieso, 2008). Se iniciaba el recorrido

\footnotetext{
Señora, pp. 109-134.

${ }^{24}$ Antonio Arbiol. La familia regulada..., ob. cit., libro IV, capítulo 22.

${ }^{25}$ Pantaleón García. Sermones panegíricos..., op. cit., Sermón VIII del Rosario de María Santísima, pp. 195-234.

${ }^{26}$ Al respecto, Martínez de Sánchez afirma que Córdoba dispuso de apoyo bibliográfico para la redacción de los sermones, y el clérigo José Rosa de Córdoba contaba con algunos libros de Cristóbal de Avendaño (1787). Cfr. AHPC, Escribanía 1, leg. 419, exp. 1. “El purgatorio...”, op. cit., pp. 119-141.

${ }^{27}$ IEA, doc. $\mathrm{n}^{\circ} 11.707$, f. 2 r.

${ }^{28}$ Cristobal de Avendaño. Sermones para algunas festividades de las mas solemnes de los Santos, predicados en la Corte de Madrid. Barcelona, Francisco Pascual, 1626, p. 26.
} 
con el recuerdo de su infancia y la forma en que había sido presentada en el templo a la edad de tres años, para que quedara claro que en ella, "se había adelantado el uso de la razón, y de la libertad desde el instante primero de su vida instruida perfectamente del Espíritu Santo acompañó esta augusta ceremonia con los actos meritorios de las más heroicas virtudes" 29 .

Ella sería posteriormente, en su etapa adulta, definida como, "una criatura a quien no derribó la culpa original, a quien no acaloró el fuego de la concupiscencia, a quien no afeó la mancha de un pecado venial; y de la Virgen no debe hablarse cuando se trata del pecado; dice el Concilio de Trento: es una alma hija, del Padre, esposa del Espíritu Santo, corredentora de los hombres, reconciliadora del universo, la obra maestra del Omnipotente, dicen las sagradas Sanciones de Efeso. ¿Queréis saber quién es María? Responded ¡dice San Anselmo, es Madre de Jesús: es Madre del Verbo encarnado: es Madre de Dios: esto decide la cuestión" 30 .

Adviértase la manera en que las cualidades de su persona pasan a congregarse en torno a su condición de "Madre del Verbo encarnado".

En los episodios vinculados a la natividad de Cristo, el Niño Jesús aparece como protagonista fundamental pero siempre unido a la condición materna de la Virgen. Era el "hijo del Altísimo", a quien María había concebido en sus entrañas, luego del anuncio del ángel, de tal forma, que referirse a él implicaba a su vez rescatar las cualidades de la Virgen, que había sabido aceptar los designios divinos: "y siendo verdadero Hijo de María, sacó de su seno, y demostró a buena luz las cualidades brillantes de su Madre"31.

Y así como la vida en las comunidades se presentaba unánimemente cristiana, la Sagrada Familia era recuperada en los relatos, como modelo ejemplar.

"La estrella de Jacob había de esparcir sus primeros rayos sobre belén; y Jerusalén tenia vueltos los ojos hacia esta tierra venturosa, de donde esperaba su libertad. Dios fia de Josef el que este oráculo se cumpla: Josef guiara a esta santa familia, para que se detenga en Belen, estando ya María cercana al parto: la vara de Josef echara raíces en la tierra de sus padres, y el niño en quien sus ascendientes tenían puesta sus esperanza, conocera al nacer el origen de su linaje" ${ }^{\prime 2}$.

\footnotetext{
${ }^{29}$ IEA, doc. $\mathrm{n}^{\circ} 11.665$, f. $7 \mathrm{r}$.

${ }^{30}$ Pantaleón García. Sermones panegíricos..., ob. cit., Tomo I, Sermón V de la Visitación de Nuestra Señora, pp. 109-134.

${ }^{31}$ Pantaleón García. Sermones panegíricos..., ob. cit., Tomo I, Sermón V de la Visitación de Nuestra Señora, pp. 109-134.

32 Pantaleón García, Sermones panegíricos..., ob. cit., Tomo I, Sermón XI De San Josef, esposo de Nuestra Señora, pp. 302-334.
} 
En esta esfera de lo sobrenatural, era preciso resaltar ese momento, a fin de activar en los oyentes el recuerdo de ese instante en la historia de la Iglesia donde un padre y una madre aguardaban ansiosos, la llegada de su hijo.

"Pasemos al nacimiento, y a la conversación de Jesús en la tierra. ¡Qué rayos de grandeza resaltan en la Eucaristía a la sombra de estos misterios! Admiramos una Virgen, que con fecundidad milagrosa da a luz al Hombre Dios: admiramos un pequeño Niño ceñido con aquellos paños que fueron el escándalo del hereje Marcion. Sí, pero una sola vez nació Jesús de María o quantas veces renueva su nacimiento, multiplica su producción, recibe un nuevo ser sacramental sobre los altares, siempre que el Sacerdote pronuncia las palabras obradoras del prodigio! María le vio unos pocos días en el pesebre; pero en el Sacramento prolonga su existencia por todos los siglos. Los pastores, y los Magos tienen el honor de adorarle; pero no le tienen de alimentarse con su carne y su divinidad" ${ }^{\prime 3}$.

El niño modelo y precursor de todos los niños pequeños es el Niño Jesús y ligado a él la maternidad de la Virgen porque gracias a ella la pequeña infancia entra en escena. El misterio de su maternidad y del culto mariano liga a una madre con su hijo. La infancia es una infancia religiosa y lo que se procura es cristianizar las costumbres (Ariès, 1987).

No suficiente con su condición de maternidad divina, María era luego presentada como madre de toda la humanidad y capaz de vincular el mundo terrenal con el trascendente.

"Finalmente Señores, es esta amorosa Madre como una columna de fuego que con los resplandores de sus brillantes y refulgentes luces está continuamente llenando de celestiales bendiciones a sus hijos y conduciendo y guiando a sus verdaderos devotos por el desierto de este miserable mundo a la mejor tierra de promisión que es el Cielo" ${ }^{34}$.

La magnitud del rol desempeñado por la Virgen en el contexto de la historia de la Iglesia ha quedado ejemplificado en un sermón en donde se trasluce el contraste entre dos momentos centrales de su vida: la alegría que experimentó en Belén y el dolor que vivenció en el Calvario.

"Bienaventurada fui en Belén donde le parí entre gloria y placer; desventurada en el Calvario donde le vuelvo a parir en dolor y sufrimiento. Bienaventurada en Belén donde le parí como inocente; desventurada en el Calvario donde le he vuelto

\footnotetext{
${ }^{33}$ Pantaleón García, Sermones panegíricos..., ob. cit., Tomo I, Sermón II De la Sagrada Eucaristía, p. 40

${ }^{34}$ IEA, doc. $n^{\circ} 11.681$, f. 3 v.
} 
a parir como víctima del pecado. Bienaventurada fui en Belén donde le parí por una fecundidad divina; desventurada en el Calvario donde le vuelvo a parir con extremada compasión" 35 .

\section{Palabras finales}

Existen diversas investigaciones que prefieren referirse a las "infancias" a fin de incluir así la pluralidad de los mundos que rodean a los niños en diferentes épocas. Sin embargo, en estas piezas oratorias suele ser más frecuente la idea homogénea de una infancia en singular, a manera de categoría analítica prototípica y uniforme sobre lo que era y a lo que debía aspirar quien se encontraba transitando dicha etapa de su ciclo vital.

La historia de la infancia plasmada en las piezas oratorias se muestra en un doble sentido. El ámbito de la experiencia religiosa en su sentido lato, no sólo incluye la dimensión que se relaciona con lo divino, sino que es inseparable del rasgo de la comunicabilidad. Lo sagrado se difunde y el oyente/creyente debía estar en condiciones de recibir ese mensaje y por sobre todo, de comunicarlo y ponerlo en práctica en su entorno familiar.

Los sermones como emergentes materiales, son el resultado de la convergencia de diversos factores culturales que es necesario profundizar para determinar e interrelacionarlos con otros aspectos y circunstancias en torno a su gestación, producción e impacto. Por medio de ellos logramos introducirnos en un discurso que visual y auditivamente se mostraba como modélico, en consonancia con unos comportamientos que resultaban útiles a la Corona y a la Iglesia de la época. Todo este mundo discursivo se proyectaba hacia la niñez, la cual venía condicionada y determinada por la cultura del adulto, quien efectivamente era el responsable de esos niños.

Lejos de agotar el tema, el presente trabajo ha buscado ofrecer una aproximación hacia un tipo documental -los sermones- que bien podría ser incluido como una fuente valiosa en los estudios que abordan cuestiones tales como la infancia, su dimensión social y la perspectiva educativa. En suma, se aspira a continuar avanzando en esta línea de investigación, a fin de introducir otros elementos que permitan darle un nuevo estatuto ontológico, sociocultural y epistémico al sujeto niño.

\section{Fuentes utilizadas}

Colección Documental "Mons. Dr. Pablo Cabrera" de la Biblioteca Central "Elma Kohlmeyer de Estrabou" de la Facultad de Filosofía y Humanidades de la Universidad Nacional de Córdoba (Ex Instituto de Estudios Americanistas)

Sermones de Cuaresma, Semana Santa, Corpus Christi, festividades marianas y de santos, Ánimas y Difuntos y los referidos a la Confesión.

\footnotetext{
${ }^{35}$ Pantaleón García. Sermones panegíricos..., ob. cit, tomo V, Madrid: Gómez Fuentenebro y Compañía, 1805, Sermón I Del Descendimiento de la cruz y dolores de la Santísima Virgen, p. 5.
} 
Archivo Histórico de la Provincia de Córdoba:

Protocolos de Escribanos: Registros 3 y 4

Escribanías: 1, 2 y 3.

\section{Publicaciones de la época}

Aguilar, Cristóbal de fines s. XVIII. Obras, con estudio preliminar de Antonio Serrano Redonnet, Daisy Rípodas Ardanaz et al, Madrid, Atlas, Biblioteca de Autores Españoles, 2 tomos, [1989-1990].

Arbiol, Antonio R. P. Fr. 1791. La familia regulada, con doctrina de la Sagrada Escritura y Santos Padres de la Iglesia Católica, Madrid, Imprenta Real.

Avendaño, Cristóbal de 1626. Sermones para algunas festividades de las mas solemnes de los Santos, predicados en la Corte de Madrid, Barcelona, Francisco Pascual.

Barcia y Zambrana, Josef de 1727. Despertador cristiano, Madrid, por Francisco del Hierro.

García, Pantaleón. 1804-1805. Sermones panegíricos de varios misterios, festividades y santos, Madrid, Imprenta Collado, seis tomos.

Gómez de Terán, Juan Elías 1735. Infancia ilustrada y niñez instruida en todo género de virtudes christianas, morales y politicas que conducen a la santa educación y buena crianza de los niños para que se use en la escuela, Madrid, Oficina de Antonio Marin.

Terreros y Pando, Esteban de 1786-1787. Diccionario castellano con las voces de ciencias y artes, Madrid, viuda de Ibarra.

\section{Referencias bibliográficas}

Amador Baquiro, J. C. 2012. “Condición infantil contemporánea: hacia una epistemología de las infancias”. En: Pedagogía y Saberes, No 37, Bogotá, Universidad Pedagógica Nacional, pp. 73-87.

Arce Escobar, V. 2009. "El sermón. Palabra dramatizada y control social. Antonio Ossorio de las Peñas, un predicador en la Nueva Granada del siglo XVII”. En: Historia y espacio, № 32, Cali, Departamento de Historia de la Universidad del Valle, pp. 1-23.

Ariès, P. 1987. El niño y la vida familiar en el Antiguo Régimen, Madrid, Taurus Ediciones.

Bocanegra Acosta, E. M. 2007. "Las prácticas de crianza entre la colonia y la Independencia de Colombia: los discursos que la enuncian y las hacen visibles". En: Revista Latinoamericana de Ciencias Sociales, Niñez y Juventud, Vol. 5, N 1, Manizales, Universidad de Manizales, pp.1-20.

Caspard, P. 2001. "La infancia, la adolescencia, la juventud: para una economía política de las edades desde la época moderna". En: Lucía Martínez Moctezuma. La infancia y la cultura escrita, México, D.F., Siglo XXI, pp. 77- 100. 
Chinchilla Pawling, P. 2004. De la 'compositio loci' a la república de las letras: predicación jesuita en el siglo XVII novohispano, México, Universidad Iberoamericana.

García Bernal, J. 2008. "El templo y el imaginario festivo del Barroco: a propósito de la descripción panegírica de Núñez Sotomayor”. En: Studia Histórica, Historia Moderna, No 30, Salamanca, Universidad de Salamanca, pp. 273-318.

García García, F. 2005. "Una aproximación a la historia de la retórica". En: Ícono 14: Revista de Comunicación y Nuevas Tecnologías, [En línea], Vol. 3, N ${ }^{\mathrm{o}} 2$, consultado el 15 de marzo 2016. URL: http://www.icono14.net/ojs/index.php/ icono14

Ghirardi, M. e Irigoyen López, A. 2009. "El matrimonio, el Concilio de Trento e Hispanoamérica". En: Revista de Indias, Vol. LXIX, No 246, Madrid, Centro de Ciencias Humanas y Sociales, pp. 241-272.

Gonzalbo Aizpuru, P. 1998. Familia y orden colonial, México, El Colegio de México.

Gutiérrez Gutiérrez, A. y Pernil Alarcón, P. 2013. Historia de la infancia. Itinerarios educativos, Madrid, Universidad Nacional de Educación a Distancia.

Marimón Llorca, C. 2006. El texto argumentativo, Madrid, Liceus.

Marín Guadarrama, N. 2012. "La crianza infantil en los discursos coloniales indígenas en el México Central". En: Ra Ximhai, Revista cientifica de sociedad, cultura y desarrollo sostenible, Vol. 8, No 3, México, Universidad Autónoma Indígena de México, pp. 65-87.

Martínez de Sánchez, A. M. 2013. "Púlpito y confesionario: los espacios de la persuasión”. En: Ana María Martínez de Sánchez (Dir.) Cátedra, púlpito y confesionario. Hacer y decir los sermones, Córdoba, Centro de Investigaciones y Estudios sobre Cultura y Sociedad, pp. 9-30.

Páez Morales, G. 2006. Familia, infancia y sociedad en la colonia neogranadina. Estudio sociológico e histórico, Bogotá, Universidad Santo Tomás.

Pedraza Gómez, Z. 2007. "El trabajo infantil en clave colonial: consideraciones histórico-antropológicas”. En: Nómadas, № 26, Colombia, Universidad Central, pp. 80-90.

Sanchiz, J. 2005. "La nobleza y sus vínculos familiares". En: Pilar Gonzalbo Aizpuru (Dir.) Historia de la vida cotidiana en México, Tomo II, México, El Colegio de México y Fondo de Cultura Económica, pp. 335-369.

Sanchiz, J. 2005. "La nobleza y sus vínculos familiares". En: Pilar Gonzalbo Aizpuru (Dir.) Historia de la vida cotidiana en México, Tomo II, México, El Colegio de México y Fondo de Cultura Económica, pp. 335-369.

Schaefer, R. T. 2006. Introducción a la Sociología, Madrid, McGraw Hill.

Terán Fuentes, M. 2002. El artificio de la fe. La vida pública de los hombres del poder en el Zacatecas del siglo XVIII, México, Instituto Zacatecano de la Cultura, Universidad Autónoma de Zacatecas.

Valdivieso, E. 2008. "La Santa Infancia en la pintura barroca sevillana". En: Boletín de la Real Academia Sevillana de Buenas letras, №36, Sevilla, Universidad de Sevilla, pp. 9-32. 